\title{
A knowledge-based approach to the layout optimization of human-robot collaborative workplace
}

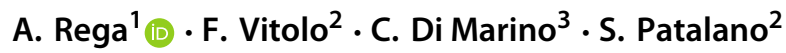

Received: 12 March 2020 / Accepted: 7 October 2020 / Published online: 22 October 2020

(c) The Author(s) 2020

\begin{abstract}
Human-robot collaboration (HRC) solutions are replacing classic industrial robot due to the possibility of realizing more flexible production systems. Collaborative robot systems, named cobot, can work side by side with humans combining their strengths. However, obtaining an efficient HRC is not trivial; indeed, the potential advantages of the collaborative robotics increase as complexity increases. In this context, the main challenge is to design the layout of collaborative workplaces facing the facility layout problem and ensuring the safety of the human being. To move through the high number of safety standards could be very tiring and unproductive. Therefore, in this work a list of key elements, linked to reference norms and production needs, characterizing the collaborative workplace has been identified. Then, a graph-based approach has been used in order to organize and easily manage this information. The management by means graphs has facilitated the implementation of the acquired knowledge in a code, developed in Matlab environment. This code aims to help the designer in the layout organization of human-robot collaborative workplaces in standards compliance. The paper presents the optimization code, named Smart Positioner, and the operation is explained through a workflow diagram.
\end{abstract}

Keywords Knowledge-based approach $\cdot$ Human-robot collaboration $\cdot$ Facility layout problem $\cdot$ Optimization criteria

\section{Introduction}

Nowadays, technology innovation, challenged by industry 4.0 pillars, is pulling the manufacturing improvement $[13$, $15,16]$.

One of the most interesting challenge is the robotics improvement and its applications; in particular, the

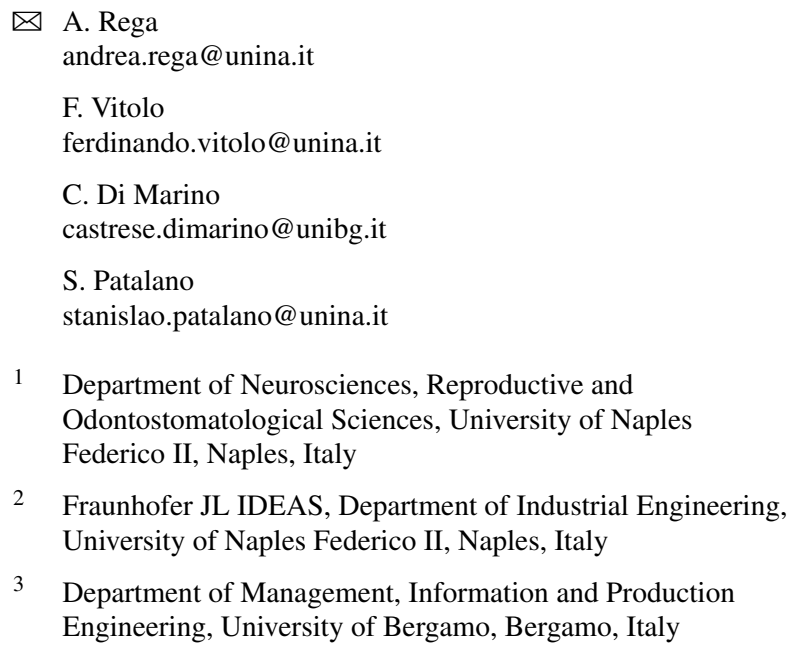

1 Department of Neurosciences, Reproductive and Odontostomatological Sciences, University of Naples Federico II, Naples, Italy

2 Fraunhofer JL IDEAS, Department of Industrial Engineering, University of Naples Federico II, Naples, Italy

3 Department of Management, Information and Production Engineering, University of Bergamo, Bergamo, Italy

human-robot collaboration (HRC) tasks. HRC is based on two resources, human being and collaborative robot (cobot), that work side by side [17] to perform a common task.

A cobot is a special kind of robot, environmentally aware, which can share the workspace with other cobots or with human operators. Sometimes it is equipped with vision system, sensitive skin and proximity or contact sensors [3]. They are very suitable for light and repetitive activities in limited space where human presence is allowed. On another hand, they must work with low speed and payload and consequently with a limited productive capability. However, the combination of human and robot strengths allows to achieve more flexible production processes maintaining the repeatability and accuracy of classic industrial automation [2].

The implementation of collaborative robotics is still a challenge due to a significant increase in complexity [8]. Indeed, the human presence in the workplace involves consideration of aspects that go beyond the robotics alone.

In this context, the facility layout problem of the HRC workplaces is one of the most interesting technical challenge $[10,12]$ to face in order to achieve an efficient collaboration between humans and cobots [4]. Pini et al. [11] propose a systematic approach to identify the resources more suitable 
to perform the different tasks, but the organization of the layout is left to the designer perception. Other researchers $[9,14]$ face the task allocation to humans and robots, but the layout design is not deeply tackled.

Furthermore, the above-mentioned approaches do not face the regulatory constraints and the compliance with standards in the methods and tools they have developed. Therefore, this work, through the analysis and the critical study of the reference frame, proposes a knowledge-based approach aimed to help the designer to move among the complex regulatory framework in order to develop a compliance HRC layout.

\section{Standards and constraints}

Ensuring safety of the human being in workplaces is the main challenge to tackle. The International Organization for Standardization faced the safety problem providing a huge amount of rules and prescriptions strongly interconnected [5-7]. However, it is very hard to move among the maze of standards that sometimes are merely guideline [1]. Even though, in the international standards, all the spaces within the workplace are defined, the operating space, that is the space where the task sequence is carried out, is exclusively dedicated to the robot, whereas the collaborative space, where human presence is permitted and the interaction between human and robot can occur, is only a portion of it. On the other hand, the definition of these spaces does not consider the human presence, indeed the collaborative operations described in the standards are all robot oriented, due to safety reasons.

Many other prescriptions and constrains shall be considered from standards and production needs. All these elements can be summarized in the following list: (1) type of operation; (2) physical limits and clearance; (3) environmental conditions; (iv) ergonomic limits; (5) human intervention and tasks; (6) robot parameters; (7) material feature and conditions; (8) workspaces division; (9) safeguarding perimeter and accesses; and, (10) devices and resources.

To comply all these aspects is not easy, therefore the designing is left to the experience of the designer and the commercial software have no constrain implemented to comply the standard prescriptions.

\section{Tools}

Several instruments and tools can be used to face the challenges about human-robot collaboration workplace design. Through several engineering design methods, such as axiomatic design and graph theory, it is possible to extrapolate the basic concepts of a collaborative workplace, to find the requirements defined by the standards and to link each of them to a design parameter. Then, all this information needs to be organized and managed. The relationships among the elements can be organized by a matrix (graph) to exploit and manipulate this knowledge.

The easily implementation and the large number of implemented codes give this graph-based tool back very powerful. Commercial software, such as Simulink (a MATLAB-based graphical programming environment), provide several algorithms in order to obtain desired results according to the inputs provided.

Finally, it is possible to generate a digital mock-up of the collaborative workplace and explore it in virtual environment in order to perform a design review.

\section{The proposed approach and results}

This work proposes the layout design and optimization of human-robot collaborative workplaces based on the knowledge of the functional requirements and constraints imposed by the reference standards. The interdependence among the huge amount of design parameters and functional requirements are managed by means a multi-level graph-based approach. The graph-based approach allows easy implementation of the knowledge in a calculation code aiming to obtain the layout of human-robot collaborative workplaces in a semi-automatic way and in standards compliance.

The calculation code, named Smart Positioner, has been developed in Matlab environment. Figure 1 depicts the flow chart showing the functioning of the Smart Positioner. It is characterized by four main steps: (S1) manually inputs insertion-the designer inserts as inputs: (1) cell dimensions, (2) resources characteristics (number, type and dimensions), (3) tasks sequence. (S2) Generation of the HRC workplace layout in a three-dimensional environment. The tool performs a first check on the generated solution to assure compliance with the regulations. The layout visualization is also available in a $2 \mathrm{D}$ environment in order to allow easier control of the overall dimensions and visual obstructions. (S3) Customization by the designer: the tool allows the user to evaluate and edit the layout. Then a check occurs to verify the standards compliance. (S4) Conversion of the file to JT (Jupiter Tessellation) format in order to export it to simulation environments. This tool provides a crucial support to the designer to move through the complexity of the huge amount of constraints and requirements of the standards.

The resources of the workplace are organized using optimisation criteria due to minimize the floor space occupied, the distance covered by the operator and the material handling costs, under constraint of minimum distances to comply.

Definitely, the proposed Smart Positioner represents a useful tool to reach an efficient human-robot collaboration, 


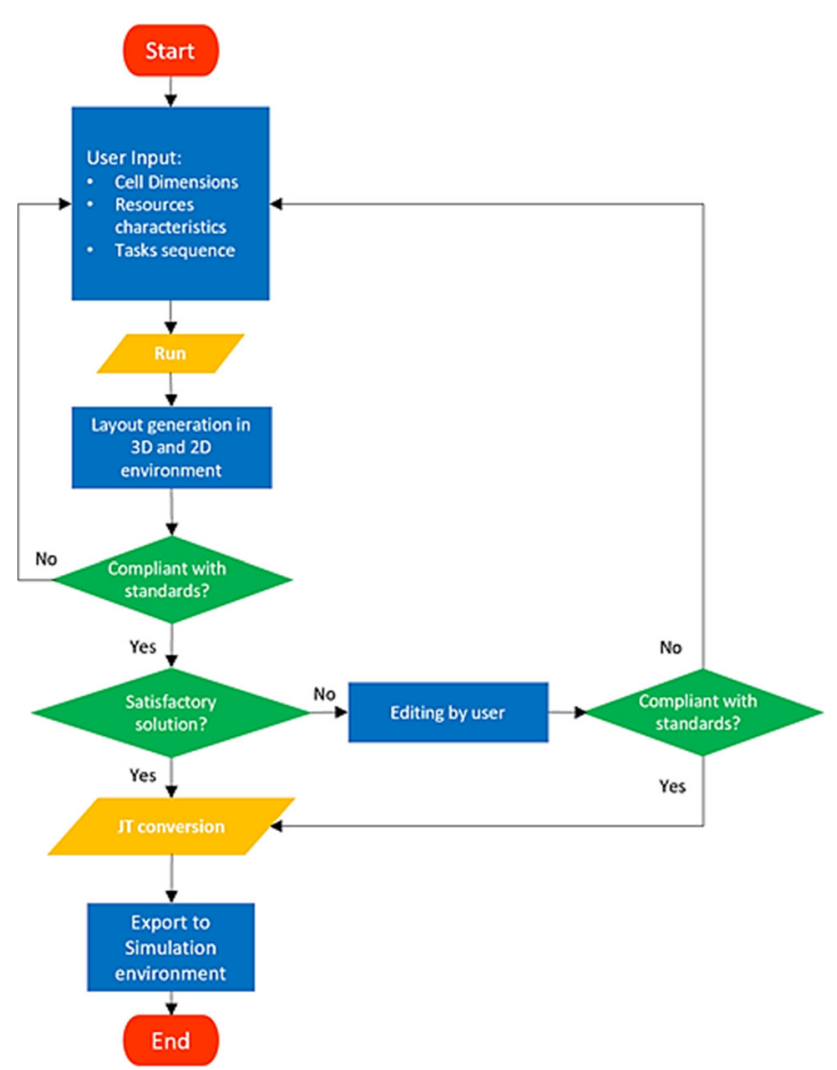

Fig. 1 Smart Positioner flow chart

facing the layout design problem of the collaborative workplaces by means a knowledge-based approach.

Funding Open access funding provided by Università degli Studi di Napoli Federico II within the CRUI-CARE Agreement.

Open Access This article is licensed under a Creative Commons Attribution 4.0 International License, which permits use, sharing, adaptation, distribution and reproduction in any medium or format, as long as you give appropriate credit to the original author(s) and the source, provide a link to the Creative Commons licence, and indicate if changes were made. The images or other third party material in this article are included in the article's Creative Commons licence, unless indicated otherwise in a credit line to the material. If material is not included in the article's Creative Commons licence and your intended use is not permitted by statutory regulation or exceeds the permitted use, you will need to obtain permission directly from the copyright holder. To view a copy of this licence, visit http://creativecomm ons.org/licenses/by/4.0/.

\section{References}

1. Bdiwi, M., Pfeifer, M., Sterzing, A.: A new strategy for ensuring human safety during various levels of interaction with industrial robots. CIRP Ann. Manuf. Technol. 66(1), 453-456 (2017)

2. Di Marino, C., Rega, A., Vitolo, F., Patalano, S., Lanzotti, A.: The anthropometric basis for the designing of collaborative workplaces. In: 2019 IEEE International Workshop on Metrology for Indus- try 4.0 and IoT, MetroInd 4.0 and IoT 2019-Proceedings, (1), pp. 98-102 (2019)

3. Djuric, A.M., Rickli, J.L., Urbanic, R.J.: A framework for collaborative robot (CoBot) integration in advanced manufacturing systems. SAE Int. J. Mater. Manuf. 9(2), 457-464 (2016)

4. Heydaryan, S., Bedolla, J.S., Belingardi, G.: Safety design and development of a human-robot collaboration assembly process in the automotive industry. Appl. Sci. (Switzerland) 8(3), 0-22 (2018)

5. ISO, ISO/TS 15066: 2016: Robots and Robotic DEVICESCOLLABORATIVE ROBOTS. Geneva: International Organization for Standardization (2016)

6. ISO, ISO 10218-1: 2011: Robots and Robotic Devices-Safety Requirements for Industrial Robots-Part 1: Robots. Geneva: International Organization for Standardization (2011)

7. ISO, ISO 10218-2: 2011: Robots and Robotic Devices-Safety Requirements for Industrial Robots-Part 2: Robot Systems and Integration. Geneva: International Organization for Standardization (2011)

8. Krüger, J., Wang, L., Verl, A., Bauernhansl, T., Carpanzano, E., Makris, S., Fleischer, J., Reinhart, G., Franke, J., Pellegrinelli, S.: Innovative control of assembly systems and lines. CIRP Ann. 66(2), 707-730 (2017). https://doi.org/10.1016/j.cirp.2017.05.010

9. Mateus, J.C., Claeys, D., Limère, V., Cottyn, J., Aghezzaf, E.H.: A structured methodology for the design of a human-robot collaborative assembly workplace. Int. J. Adv. Manuf. Technol. 102(5-8), 2663-2681 (2019)

10. Michalos, G., Spiliotopoulos, J., Makris, S., Chryssolouris, G.: A method for planning human robot shared tasks. CIRP J. Manuf. Sci. Technol. 22, 76-90 (2018)

11. Pini, F., Leali, F., Ansaloni, M: A systematic approach to the engineering design of a HRC workcell for bio-medical product assembly. In: 2015 IEEE 20th Conference on Emerging Technologies \& Factory Automation (ETFA), pp. 1-8. IEEE (2015)

12. Papakostas, N., O'Connor Moneley, J., Hargaden, V.: Integrated simulation-based facility layout and complex production line design under uncertainty. CIRP Ann. 67(1), 451-454 (2018)

13. Rega, A., Patalano, S., Vitolo, F., Gerbino, S.: A sensor data fusionbased locating method for reverse engineering scanning systems. In: 2019 II Workshop on Metrology for Industry 4.0 and IoT (MetroInd4. 0\&IoT). IEEE, pp. 123-126 (2019)

14. Tsarouchi, P., Michalos, G., Makris, S., Athanasatos, T., Dimoulas, K., Chryssolouris, G.: On a human-robot workplace design and task allocation system. Int. J. Comput. Integr. Manuf. 30(12), 1272-1279 (2017)

15. Vitolo, F., Franciosa, P., Ceglarek, D., Patalano, S., De Martino, M.: A generalised multi-attribute task sequencing approach for robotics optical inspection systems. In: 2019 II Workshop on Metrology for Industry 4.0 and IoT (MetroInd4. 0\&IoT), pp. 117-122. IEEE (2019)

16. Vitolo, F., Patalano, S., Rega, A., \& Lanzotti, A.: An autonomous and self-locating handling device for reverse engineering systems. In: 2019 20th International Conference on Research and Education in Mechatronics (REM), pp. 1-7. IEEE (2019)

17. Villani, V., Pini, F., Leali, F., Secchi, C.: Survey on human-robot collaboration in industrial settings: safety, intuitive interfaces and applications. Mechatronics 55(February), 248-266 (2018)

Publisher's Note Springer Nature remains neutral with regard to jurisdictional claims in published maps and institutional affiliations. 